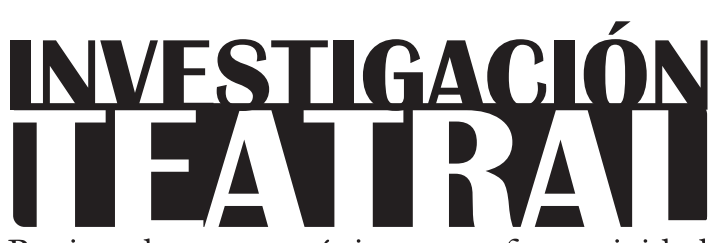

Revista de artes escénicas y performatividad

Vol. 9, Núm. 14

octubre 2018-marzo 2019

Segunda época

ISSN impreso: 1665-8728

ISSN electrónico: 2594-0953

Universidad Veracruzana

Testimonio:

\title{
Maquillaje escénico desde la perspectiva de la innovación educativa para las artes
}

Juliana Welasco Santana*

\footnotetext{
* Universidad Veracruzana, México. e-mail: juliana.welasco@gmail.com
}

Recibido: 18 de abril de 2018

Aceptado: 12 de junio de 2018 
INVESTIGACIÓNTEATRAL

Revista de artes escénicas y performatividad

Vol. 9, Núm. 14

octubre 2018-marzo 2019
Maquillaje escénico desde la perspectiva de la innovación educativa para las artes

Juliana Welasco Santana

\title{
Maquillaje escénico desde la perspectiva de la innovación educativa para las artes
}

\section{Resumen}

El presente testimonio relata la experiencia práctica que tuvo la autora como docente en un curso de maquillaje escénico que impartió para estudiantes de la Licenciatura de Danza Contemporánea de la Universidad Veracruzana en abril de 2018. Se reflexiona sobre la teoría y estética del maquillaje y la pertinencia que puede tener como propuesta de innovación educativa para las artes.

Palabras clave: maquillaje escénico, educación, caracterización, estética, lenguaje visual, semiótica.

\section{Stage Makeup as a Proposed Educational Innovation for the Arts}

\begin{abstract}
In this testimony, the author tells about her practical experience as a teacher in a Stage Makeup course for students of the Bachelor's Degree in Contemporary Dance at the Veracruzana University, Xalapa, in April 2018. The theory and aesthetics of makeup, and the relevance it has as a proposed educational innovation for the arts, are discussed.
\end{abstract}

Keywords: stage makeup, education, characterization, aesthetics, visual language, semiotics. 


\section{Maquillaje escénico desde la perspectiva de la innovación educativa para las artes}

\section{El maquillaje escénico en el contexto de la Universidad Veracruzana}

$\mathrm{E}$

n la Universidad Veracruzana, las carreras de Teatro y Danza no cuentan en sus planes de estudios con experiencias educativas propias de la escenotecnia, ${ }^{1}$ en particular de maquillaje escénico, vestuario y caracterización (todo lo cual forma parte del lenguaje técnico y visual del quehacer escénico).

Ante dicha carencia, la directora de la Facultad de Danza, Nahomi Bonilla, me extendió la invitación para dar un curso de maquillaje escénico para estudiantes de la Licenciatura en Danza Contemporánea. Además de contribuir al aprendizaje de los estudiantes de Danza, la idea era que yo pudiera aportar también algo a la mesa plenaria sobre innovación educativa para las artes, a partir de la experiencia que desarrollaría con los estudiantes a lo largo del curso.

Con base en la propuesta temática de la "innovación educativa para las artes", diseñé un curso teórico-práctico con el propósito de dar a los estudiantes un contenido lúdico y a su vez eficiente, que pudiera ser aplicado en sus labores escénicas futuras. A partir de algunos conceptos abordados en mi tesis de maestría "El maquillaje escénico en las poéticas contemporáneas: aspectos presentes en Drag Queen y Clown", me propuse asociar la teoría y la práctica de manera que pudiesen caminar juntas. Conceptos de disciplinas como la

1 De acuerdo con Álvaro Horcas García, "Escenotecnia se entiende por equipo, materiales y normas para la arquitectura, mecánica, carpintería, decorado, iluminación, vestuario, maquillaje, utilería y cuanto contribuye al ambiente y clima en teatro, danza, cine y televisión” (“Escenotecnia”, párr. 2). 


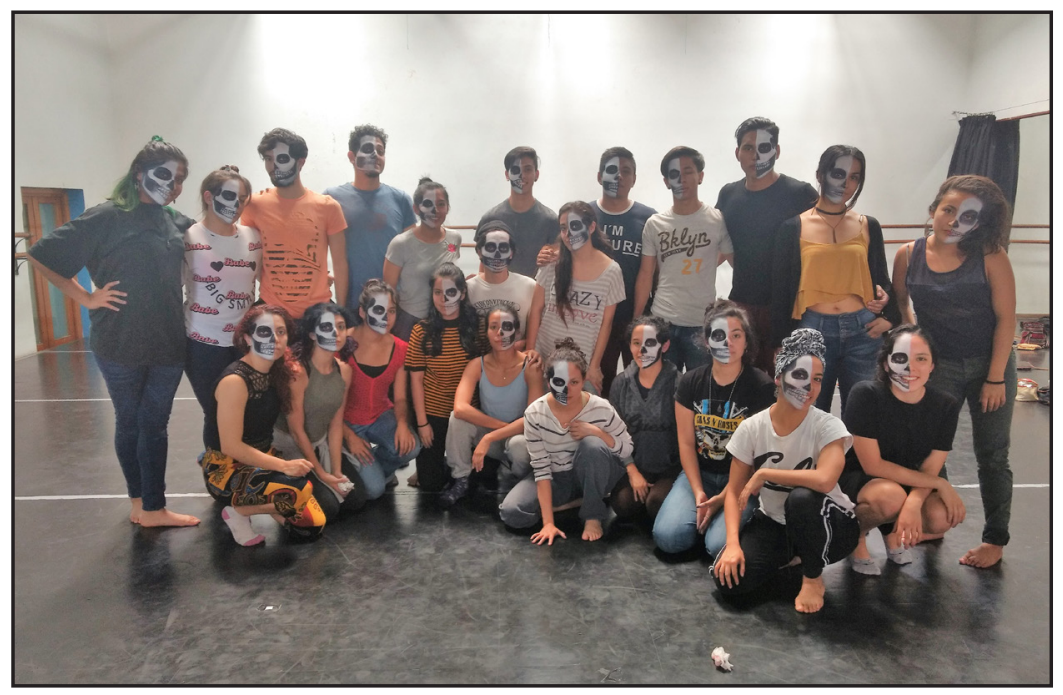

Estudiantes de danza de la Universidad Veracruzana en el taller de Maquillaje Escénico. Xalapa, Veracruz, 2018. Fotografìa de Juliana Welasco.

estética, el lenguaje visual, la semiótica, la caracterización visual y otros, fueron utilizados ampliamente en el curso impartido, lo que nos permitió elaborar reflexiones sobre el maquillaje más allá de la práctica, desde un enfoque académico.

\section{Maquillaje escénico para estudiantes de Danza}

El curso y las técnicas aplicadas fueron planeados de tal manera que pudieran ser útiles a los estudiantes de la carrera de Danza, en general, pues estaban presentes tanto alumnos del primer semestre de la carrera, como estudiantes en el cierre de su proceso formativo.

Entre los integrantes del grupo, había quienes nunca habían tenido contacto con el maquillaje -ni con los materiales ni con las técnicas-, así como alumnos que conocían algo al respecto. Mi percepción fue que el grupo mostraba curiosidad y disposición ante los desafíos de una disciplina que exige la habilidad técnica del dibujo y la sensibilidad del trabajo con colores (algo aparentemente lejano a los propósitos inmediatos de un artista escénico que quiere dedicarse a la danza).

\section{Maquillaje escénico: la estructura del curso}

El curso fue planeado para cinco días, con una duración total de 15 horas, es decir, sesiones de 3 horas cada día. Por tratarse de un taller intensivo, me planteé las siguientes preguntas: 
¿qué me gustaría aprender de maquillaje si solamente tuviera una semana?, ¿cuáles son las técnicas más útiles para quien está empezando?, ¿cómo compartir un conocimiento que sea lúdico, pero, al mismo tiempo, eficaz? A partir de estos cuestionamientos diseñé todo el programa, así como la didáctica que iba a ser implementada a partir de las técnicas que -desde mi perspectiva- serían las más útiles.

Empecé con las técnicas básicas. A lo largo de las clases, con la percepción de las habilidades y la dinámica, fui agregando técnicas más avanzadas. En todas las clases había una parte teórica y otra práctica: la primera tenía como propósito introducir conceptos esenciales del maquillaje, con base en lo abordado en mi tesis de maestría; la segunda fue el espacio donde los estudiantes pudieron ejercitar todo lo estudiado en la teoría. Así logré desarrollar un plan teórico-práctico.

\section{El temario del curso: recapitulación de la experiencia educativa}

La primera sesión fue estructurada en torno a una breve historia del maquillaje, a modo de introducción, y la instrucción de cómo aplicar correctamente sobre la piel los materiales que íbamos a ocupar. También entramos un poco al estudio de la anatomía de la cara: la estructura ósea, las cavidades y protuberancias. Para buscar la estructura ósea en el rostro, los estudiantes fueron orientados a dibujar una calavera sobre la cara, invitados mediante esta actividad a percibir sus rasgos y huesos. Utilizamos para ello la técnica de luz y sombra, con cremas de colores en tonos café, negro y blanco.

En la segunda sesión abordamos la teoría de los colores, presentando a los estudiantes el círculo cromático, con el objetivo de que pudieran distinguir entre colores primarios, secundarios y terciarios, e identificar las posibilidades existentes entre ellos. Se presentaron en seguida los colores complementarios y análogos -además de sus matices y graduaciones de tonos-, a través de una demostración de cómo mezclar colores y adquirir diferentes tonos con las cremas que estábamos ocupando. Ese día, los estudiantes reprodujeron un maquillaje basándose en diferentes culturas (japonesa, india, indígena brasileña, mexicana, africana, entre otras -lo que llamamos maquillajes étnicos-); el propósito de la actividad era que pudieran explorar técnicas para mezclar colores, así como para hacer líneas y formas en concordancia con cada una de esas tradiciones.

En la tercera sesión - con la experiencia aprehendida de la anatomía de la cara humana, más la familiarización con la teoría de los colores, las líneas y las formas-, los estudiantes representaron la cara de algún animal en el rostro humano, considerando los matices cromáticos, las profundidades, los volúmenes y las texturas de plumas, pelos y escamas. 
INVESTIGACIÓNTEATRAL

Revista de artes escénicas y performatividad

Vol. 9, Núm. 14

octubre 2018-marzo 2019
Maquillaje escénico desde la perspectiva de la innovación educativa para las artes

Juliana Welasco Santana

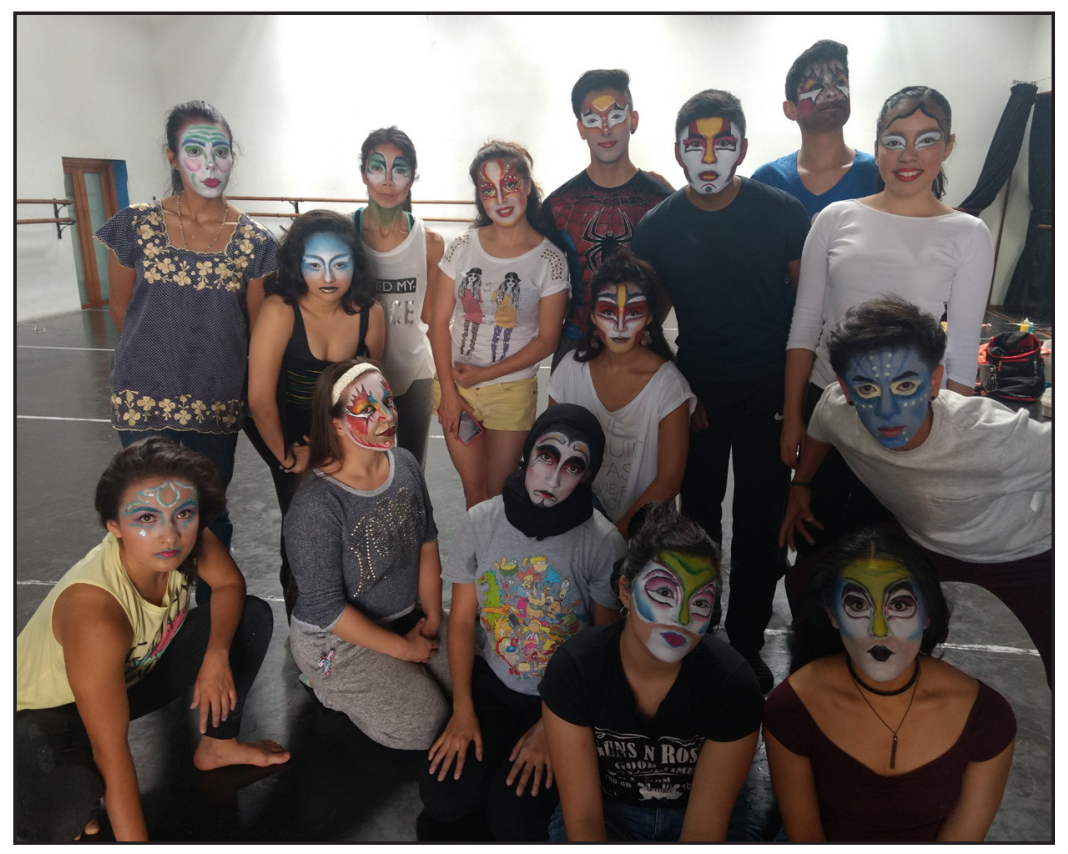

Estudiantes de danza de la Universidad Veracruzana en el taller de Maquillaje Escénico. Xalapa, Veracruz, 2018, México. Foto por: Juliana Welasco.

Durante la cuarta sesión, fueron presentados algunos maquillajes de diferentes espectáculos del Cirque du Soleil (por lo regular se trata de maquillajes de fantasía inspirados en animales, flores, plantas, frutas, etcétera). Los estudiantes reprodujeron un maquillaje con tales características para practicar las técnicas de las clases anteriores, pero también para comprender cómo se hace un maquillaje de fantasía. Las técnicas de mayor relevancia en esta actividad fueron: las líneas, los difuminados, los degradados, la mezcla de colores, los volúmenes y profundidades.

Para finalizar, en la quinta sesión fueron presentados conceptos del lenguaje visual y sus principales características en la escena. Pedí a los estudiantes que concibieran libremente un maquillaje y ejercitaran su capacidad creativa: se trataba de crear o recrear un maquillaje con la aplicación de las técnicas estudiadas a lo largo de todo el curso.

\section{El maquillaje escénico y la innovación educativa para las artes}

Desde mi experiencia, pensar en la innovación educativa para las artes consiste en develar la relevancia de que la teoría y la práctica caminen juntas. Además de leer conceptos y reflexionar sobre ellos, implica generar las condiciones para aterrizar tales conceptos en la realidad práctica de los estudiantes. 
Lo anterior implica, en el caso del maquillaje, abordarlo en su dimensión de lenguaje visual que influye en la escena. Cuando presenté a los estudiantes del curso la teoría de los colores y sus posibilidades, ellos pudieron ponerla en práctica al ensayar algunas mezclas y descubrir nuevas coloraciones o tonos del mismo color; hicieron una paleta cromática, además de comprender cómo los colores del espacio escénico, vestuario y maquillaje dependen de la iluminación y cómo la luz está directamente conectada al lenguaje visual de la escena.

A pesar de haber sido un curso intensivo de corta duración, mi apuesta como docente fue transmitir un contenido útil, tanto para los estudiantes que estaban apenas iniciando su carrera, como para aquellos que estaban por ingresar al mercado profesional. La intención no era formar especialistas del maquillaje, sino presentarles el lenguaje y las técnicas para que ellos pudieran reflexionar sobre los aspectos visuales de la puesta en escena y aplicar esta experiencia en sus quehaceres artísticos o académicos.

\section{La socialización de los hallazgos: mesa plenaria de cierre}

Para finalizar el segundo Foro, el día viernes 13 de abril todos los maestros participantes tuvimos la oportunidad de compartir nuestras experiencias en la mesa plenaria, enfocada en discutir en torno a la innovación educativa de las artes, de acuerdo con nuestras respectivas actividades y enfoques. Debo acotar que se invitó a un maestro de cada facultad a trabajar específicamente con los estudiantes de su área, como fue mi caso con los de la Facultad de Danza.

Un punto muy recurrente a través de los discursos de los compañeros maestros fue justamente el desafío que representa unir la teoría con la práctica; también expusieron las características, antecedentes y objetivos de sus cursos, así como el abordaje elegido con los estudiantes. Mi intervención giró en torno a los desafíos metodológicos que el área de las artes enfrenta desde la disciplina del maquillaje escénico. En el ámbito académico, considero que esta disciplina debe ser direccionada para apoyar la estética visual del espectáculo; sin embargo, hay que tener una interrelación con otras áreas técnicas como el vestuario, la escenografía y, principalmente, la iluminación, correlacionando los elementos visuales en armonía.

$\mathrm{Al}$ escuchar a los colegas participantes, sentí que diferentes áreas de las artes poseen dificultades similares y que la mesa fue un evento enriquecedor para todos los que participamos, como lo fueron también las actividades del Foro de Innovación Educativa para las Artes. Considero que se trató de una iniciativa muy importante por parte de la Universidad Veracruzana, donde se generó la posibilidad de que los estudiantes se aproximaran a otros 
INVESTIGACIÓNTEATRAL

Revista de artes escénicas y performatividad

Vol. 9, Núm. 14

octubre 2018-marzo 2019
Maquillaje escénico desde la perspectiva de la innovación educativa para las artes

Juliana Welasco Santana

lenguajes artísticos, dándoles a conocer diversas maneras de complementar sus carreras con otras áreas artísticas. Además, permitió el intercambio de experiencias entre los maestros participantes.

Me quedo con la sensación de gratitud por esa semana intensiva que pasé junto a los estudiantes de Danza, pues también tuve la oportunidad de compartir parte de mi investigación académica desarrollada en la Maestría en Artes Escénicas de la propia Universidad (no suele haber muchos espacios para interrelacionarse de ese modo con los estudiantes de las licenciaturas en artes). Espero que se sigan abriendo este tipo de espacios para que pensemos juntos en otras formas de innovar en la formación artística de estudiantes y del cuerpo docente de la Universidad Veracruzana.

\section{Bibliografía}

Horcas García, Álvaro. “Escenotecnia”. Artes Escénicas. Octubre de 2009, en línea. Consultado el 8 de agosto de 2018.

Welasco Santana, Juliana. "El maquillaje escénico en las poéticas contemporáneas: aspectos presentes en Drag Queen y Clown". Tesis de maestría, Facultad de Teatro, Universidad Veracruzana, 2017. 